\title{
MicroRNA expression profiling in PBMCs of Indian water Buffalo (Bubalus bubalis) infected with Brucella and Johne's disease
}

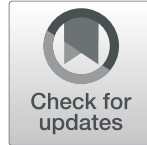

\author{
Jasdeep Singh ${ }^{1,2}$, Jasdeep Kaur Dhanoa', Ratan K Choudhary ${ }^{1}$, Amarjit Singh ${ }^{3}$, Ram Saran Sethi', \\ Simarjeet Kaur ${ }^{4}$ and Chandra Sekhar Mukhopadhyay ${ }^{1 *}$ (D
}

\begin{abstract}
Background: MicroRNAs play key roles in host-pathogen-interactions and disease pathogenesis. Our aim was to characterize the differentially expressed miRNAs in the blood cells of diseased (Brucellosis-positive, Johne's diseasepositive) and healthy- water buffaloes. The pooled small-RNA samples of each group were sequenced on lon Torrent Personal Genome Machine (PGM) sequencer and the data were analyzed for differential expression.

Results: Here we identified 274 known miRNAs with bovine homologs and 36 novel mature-star miRNAs from the sequnces of small RNA libraries. Overall 195 miRNAs were common to all the three groups. Certain miRNAs such as bta-miR-21-5p, -26a, -29a/b, -30d - 103, - 140, - 150, - 191, - 374, - 1434-5p,-1260b, - 2484 and let-7 members were abundantly expressed in diseased groups. Bta-miR-1434-5p, $-188,-200 \mathrm{c}$ were up-regulated ( $>1.5$ folds) while bta-miR-27a-5p, $-34 b$ and $-2285 x$ were down-regulated (> 100 folds) in Brucellosis group. In Johne's Disease group, only 3 miRNAs (bta-miR-1434-5p, - 2340 and - 2484) were up-regulated (> 1.5 folds). The functional classification of miRNA target genes into gene ontology (GO) terms indicated their involvement in innate immunity and cellular process of disease pathogenesis. Expression profile of four differentially expressed miRNAs (bta-miR-9-5p, -677, $331-3 p$ and -2440) and eight predicted target-genes were validated through reverse transcriptase qPCR.

Conclusion: This study provides a valuable frame of reference for elucidation of regulatory roles of miRNAs associated with disease pathogenesis in water buffaloes as well as identification of miRNA biomarkers for disease diagnosis and treatment.
\end{abstract}

Keywords: microRNA, RNA-Seq, Bubalus bubalis, Brucellosis, Johne's disease

\section{Background}

Circulating miRNAs have emerged as new diseasebiomarkers in human cancer [1], and in animals [2-4]. The goals of this study were to identify PBMCs miRNAs profiles in Indian water buffalo associated with economically devastating diseases, namely, brucellosis and paratuberculosis (Johne's disease or JD). Brucellosis an important zoonotic disease of livestock is caused by facultative, gram-negative bacteria of Brucella genus. This

\footnotetext{
*Correspondence: csmbioinfo@gmail.com; csmukhopadhyay@gadvasu.in ${ }^{1}$ College of Animal Biotechnology, Guru Angad Dev Veterinary and Animal Sciences University, Ludhiana, Punjab 141004, India

Full list of author information is available at the end of the article
}

intracellular organism generally enters the host via the nasal and oral routes followed by invasion and proliferation within monocytic phagocytes [5]. It spreads via macrophages to the lymph nodes, spleen, liver, bone marrow, mammary glands, and reproductive organs. Another important disease that has been encountered in dairy animals is the paratuberculosis (Johne's disease or JD) caused by Mycobacterium avium subspecies paratuberculosis (MAP). Calves mainly acquire the infection through oral route by uptake of MAP via colostrum, milk or feed contaminated with fecal matter [6] or via intrauterine route [7]. Following the invasion, the bacteria primarily resides in the mucosal tissues of gut and

(c) The Author(s). 2020 Open Access This article is licensed under a Creative Commons Attribution 4.0 International License, which permits use, sharing, adaptation, distribution and reproduction in any medium or format, as long as you give appropriate credit to the original author(s) and the source, provide a link to the Creative Commons licence, and indicate if changes were made. The images or other third party material in this article are included in the article's Creative Commons licence, unless indicated otherwise in a credit line to the material. If material is not included in the article's Creative Commons licence and your intended use is not permitted by statutory regulation or exceeds the permitted use, you will need to obtain permission directly from the copyright holder. To view a copy of this licence, visit http://creativecommons.org/licenses/by/4.0/. 
its associated lymph nodes and spreads to bloodstream, milk and other peripheral tissues [8]. MAP being an obligate intracellular pathogen resides in host macrophages and enhance its survival by inhibiting intracellular phagosomal activation and maturation $[9,10]$. Thus, Brucellosis and JD, causes substantial economic losses to livestock worldwide and hence scientific research has been focused on their diagnosis, prevention, and control.

The currently available diagnostic tests of MAP infection, which are based on assays of IFN- $\gamma$ and PCR, have the limitation of sensitivity and specificity, particularly in detecting early stage of infection [11, 12]. Therefore search for novel and alternative diagnostic biomarkers such as microRNAs for early stages of MAP infection would be beneficial.

The microRNAs (miRNAs) are short ( $22 \mathrm{nt})$, noncoding RNAs that regulate post-transcriptional expression of mRNAs of at least one-third of known mammalian genes. These miniature RNAs play an instrumental role in immune regulation and disease pathogenesis [13-15]. Moreover, circulating miRNAs in the serum or plasma has also been reported. De-regulation of certain miRNAs indicates their utilization as potential biomarkers for various types of cardiovascular, nervous system diseases and cancer [16-18]. However, their possible association with the diseases in livestock species, particularly in buffalo, is the least studied.

A plethora of reports are available on immune and cytokine responses of Brucella infected peripheral blood mononuclear cells (PBMC) which have been exploited either for diagnosis or for vaccine development [19-22]. Similarly, recent studies on transcriptional profiling of PBMCs in cattle suffering from Johne's disease have identified upregulated expression of genes (such as IL-5 \& transcription factor GATA-3) promoting growth and differentiation of hematopoietic progenitor cells and Tlymphocytes genes as well as activation of neutrophils and macrophages. Further, infection with M. paratuberculosis is shown to be associated with upregulated expression of genes (Bad, CIDE-A, Fas, TNFRI) responsible for promoting apoptosis as well as genes (tissue inhibitors of matrix metalloproteinases, TIMP-1 and TIMP-2) having role in modeling extracellular matrix and tissue [23]. Additionally, natural infection of cattle with $M$. avium paratuberculosis (MAP) resulted in upregulated expression of the $\mathrm{CD} 40$ receptor and its ligand in PBMC [24].

Some immune-related miRNAs were up-regulated in various cells in response to intracellular pathogens, viz. mycobacterium infections $[25,26]$. Further, some studies conducted in human have revealed significantly altered circulating miRNA profiles in serum of patients affected by tuberculosis than their respective healthy controls $[27,28]$. Therefore, corroborating the possiblity that other intracellular mycobacterial and Gram-negative bacterial infections including Johne's disease and Brucellosis of cattle may also alter the miRNA profiles of PBMCs. Very limited reports are available on the bubaline miRNA repertoire in context to disease. Only one such recent study characterized the serum and vaginal fluids miRNAs involved in Brucella infection in water buffaloes and implicated its use as potential disease prognostic biomarkers [29]. Recently our lab also identified isomiRs related to Brucellosis and Jhone's disease in Indian water buffaloes and classified their predicted targets based on their biological and immune functions [30,31].

In this study, we hypothesized that intracellular bacterial infections with MAP and Brucella causes significant changes in the miRNA profiles of bubaline PBMCs and profiling the repertoire of those miRNAs could help in identifying biomarker(s) for the diagnosis as well as disease resistance/susceptibility of animals. We performed next-generation sequencing of small-RNAs (sRNAs) extracted from the PBMCs of diseased (Johne's disease and Brucella infected) and healthy buffaloes. The comparison of the catalogued-miRNAs between the diseased and healthy animals further provided a reference for future studies aimed to identify disease biomarkers and to modulate the expression of specific miRNAs for the disease therapeutics. The identified differentially expressed miRNAs and their predicted target genes were validated using real-time PCR.

\section{Materials and methods}

\section{Animals}

Diseased vis-a-vis healthy water buffaloes (Bubalus bubalis) included in the study were from the dairy farm of our institution i.e. Guru Anagad Dev Veterinary and animal Sciences University (GADVASU), Ludhiana as well as other dairy farms situated in Punjab, based on the history of occurrences of Johne's disease and Brucellosis (abbreviated as "JD" and "Br", respectively). The experimental animals were adult (3 years age) male or female buffaloes of Murrah (abbreviated as "Mu") breed.

\section{Diagnosis of disease}

Animal Disease Research Centre (ADRC), GADVASU performed the disease diagnosis (Brucellosis, and Johne's disease). The Brucellosis-infected animals were diagnosed by the Rose Bengal plate test (RBPT), a rapid slide based agglutination test that detects antibodies against the smooth Brucella species particularly B. abortus, $B$. melitensis and B. suis [32]. The RBPT results were further confirmed by competitive ELISA (cELISA) using Brucella-Ab C-Elisa (Bovine) Kit (Svanova). The diagnosis of Johne's disease was done by PCR using primers (IS900/150C: CCGCTAATTGAGAGATGCGATTGG; IS900/921: AATCAACTCC AGCAGCGCGGCCTCG) 
specifically amplifying $229 \mathrm{bp}$ of target insertion sequence IS900 (i.e. present in multiple genomic copies in all M. paratuberculosis strains) [33]. The animals diagnosed positive for the diseases were segregated in different sheds of the respective herds. The experimental animals were divided into three diseased and one healthy control group:

a) Brucellosis-positive Murrah buffaloes (Br-Mu; $n=$ 2).

b) Johne's disease- positive Murrah buffaloes (JD-Mu; $n=5)$.

c) Healthy Murrah buffaloes (Ctrl-Mu; $n=4)$ as a control group.

\section{Collection of blood samples and isolation of PBMCs}

Peripharal blood samples $(15 \mathrm{ml}$ each) were aseptically collected from the jugular vein in an anticoagulant $(0.5 \mathrm{M}$ EDTA, $100 \mu \mathrm{l})$ containing collection tube $(50 \mathrm{ml})$ and were kept at $4{ }^{\circ} \mathrm{C}$ using ice packs before further processing in the laboratory. The density-based gradient centrifugation method, using Hisep 1077 (HiMedia, Mumbai, India), was foolowed for PBMC isolation. The extracted PBMCs belonging to each of the specific experimental groups (i.e. biological replicates) were pooled into one sample. Since only two animal was tested positive for Brucellosis, about $30 \mathrm{ml}$ of blood was collected from these animals in order to get approximately the same PBMCs count for all for the experimental groups. The three pooled samples of PBMCs were further processed separately for sRNA extraction and miRNA-sequencing [34].

\section{Small-RNA isolation and library preparation}

The pooled PBMCs pellets were further processed for small-RNA extraction using mirVana ${ }^{\mathrm{Tm}}$ miRNA Isolation Kit (Ambion, Life Technologies, CA, USA). The steps included organic phase extraction and RNA immobilization on glass-fiber filters to yield enriched miRNA-fraction. The sRNA samples were quantified and tested for quality on Agilent's Bioanalyzer (Agilent, CA, USA) before further processing. The electropherogram profile of each sRNA sample was obtained and the presence of degraded sRNA, as well as concentrations ( $\mathrm{pg} / \mu \mathrm{l})$ of sRNA, was checked.

The extracted sRNA samples were transported in dry ice to GCC Biotech Pvt. Ltd., Kolkata for nextgeneration sequencing (NGS). The cDNA libraries were prepared using Ion Total RNA-Seq Kit v2 and assessed for quality on an Agilent 2100 Bioanalyzer with DNA 1000 Kit (Agilent Technologies, USA). Smear analysis was carried out by utilizing 2100 expert program (Agilent Technologies, CA, USA), to determine the size distribution of the amplified DNA. For template preparation, equal molar concentration (nM) each cDNA library were immobilized on Ion Sphere Particles for sequencing on Ion $\mathrm{PGM}^{\mathrm{su}}$ Sequencer (Life Technologies, USA). The library workflow uses a proprietary technology to inhibits by-product synthesis and thus eliminating the need of the gel purification to select suitable size range. For better coverage and depth analysis, the samples were multiplexed on to two separate Ion Torrent chips (318 chip and 316 chip) .

\section{Bioinformatics analysis of miRNA-Seq data}

The workflow for quantifying miRNA transcripts included pre-processing and quality assessment of reads, mapping of reads to bovine genome, and quantification of miRNA read counts by statistical analysis, differential mRNA expression and lastly target prediction and functional characterization.

\section{Pre-processing of the raw reads}

The three cDNA libraries were sequenced and the raw sequencing data were subjected to pre-processing steps to remove low quality reads containing too many missing nucleotides or reads of inappropriate length (i.e. either less than 18 nucleotides or more than 30 nucleotides). Clean reads were further obtained by trimming adaptor sequences and saved as fastq files which records the unique sequence and its count. Further quality control check of filtered reads was performed by Kmer analyisis.

\section{Alignment to bovine genome and identification of mature as well as novel miRNAs}

Since Bubalus bubalis complete genome was not sequenced, all the filtered sequences were mapped to the cattle reference genome (Btau_4.0 assembly), which is the most closely related species to buffalo. Moreover, sRNA sequencing data generally covers sequences of tRNAs, piRNAs, snRNAs and snoRNAs and repeat sequences. So to filter out such sequences, the qualitychecked reads were then aligned to different libraries viz. Rfam database (http://rfam.xfam.org/), Repbase database (http://www.girinst.org/server/RepBase/), tRNA, hairpins and piRNA database (http://pirnabank.ibab.ac. in/about.html). To identify to known miRNAs and predict novel miRNAs, filtered reads were aligned to miRNA database i.e. miRBase Release 20 (http://www. mirbase.org/) and categorized with respect to the previously known miRNAs of Bos taurus species. For attributing imperfect Dicer processing of precursor miRNAs, certain short nucleotide extensions at $3^{\prime}$ and $5^{\prime}$ terminal were taken into account. Moreover, mutations and RNA editing sites were identified within the miRNAs by aligning the reads to pre-miRNA. Normalized read counts were calculated by taking the ratio of miRNA read counts times one million to the total number reads for 
each experimental group and then transformed to natural log scale:

$$
\log \text { read counts }=\log _{e}\left(\frac{\text { Read count of miRNA } * 1000,000}{\text { Total read counts matched in the sample }}\right)
$$

For the purpose of novel miRNA prediction, the unmapped read sequences were checked for RNA folding properties by using RNAfold programme in Vienna package and the reads aligning to parts of precursor miRNA, i.e. mature sequence, loop sequence and star sequence or miRNA* less expressed sequence, were extracted. The criteria adopted for further shortlisting such sequences as putative novel miRNA is that, it should be positioned on either arm of the folded secondary structure, have $<25 \mathrm{kcal} / \mathrm{mol}$ minimum free energy (MFE) and have conserved homologous sequences in other species.

\section{Expression profiles}

The Venn Diagrams online tool (http://bioinformatics. psb.ugent.be/webtools/Venn/) was used for graphical depiction of overlapping and uniquely expressed miRNAs the diseased and healthy groups viz. Br-Mu, JD-Mu and $\mathrm{Ctrl}-\mathrm{Mu}$, respectively. The miRNAs abundance data across the three groups, were were transformed to a logarithmic scale. The dispersion of expression profiles of the three experimental groups has been graphically presented by box-plots. The heatmaps were constructed using the R program's WGCNA package to show the expression of all the miRNAs (a total of 262) identified in three samples [35]. The expression level of each miRNA in the respective groups is depicted in accordance to color scale bar where white-orange-green-red, represents increase in expression levels.

\section{Prediction of miRNA targets and its functional characterization}

For the purpose of predicting the putative mRNA targets of differentially expressed miRNAs we used combination of three online tools viz. TargetScan [36], miRDB [37, 38] and PicTar [39]. The top few hits of each tool were screened to select only those predicted targets having a role in innate immune response and disease pathogenicity. The significance (the probability that the predicted target is conserved) of the predicted target is obtained by $\mathrm{P}_{\mathrm{CT}}(<$ 1) in TargetScan, highest target-score(s) for miRDB and highest PicTar score(s) for PicTar tools. The miRNA targets were further analysed based on the gene ontology, using online tool PANTHER Classification System (http:// pantherdb.org/) and functionally categorized into different biological processes and molecular functions [40].

\section{Validation of miRNAs and target genes expression}

Four differentially expressed miRNAs (2 miRNAs for each diseased vs. healthy groups), identified based on NGS fold-change, and a pair of predicted target genes for each of these four miRNAs (i.e. 8 target genes) were selected for experimental validation. The target genes were chosen based on the information available on their expression in PBMCs in humans (http://www.genecards. org/). These selected miRNA and miRNA-target genes were validated by qRT-PCR in an independent set of healthy and diseased buffaloes. The freshly isolated PBMCs from the blood of diseased and healthy buffaloes were individually processed using miRNeasy Minikit (Qiagen, Hilden, Germany) for total RNA that includes miRNA fraction.

\section{Reverse transcription}

For quantifying miRNA expression, cDNA was prepared from total RNA ( $1 \mu \mathrm{g}$ for each sample) using the miScript II RT kit (Qiagen, Hilden, Germany). The details of SYBR-green primer sequences for miRNAs and miRNA target genes are listed in Tables 1 and 2, respectively.

\section{Real-time PCR detection of miRNAs and target genes}

The $10-\mu \mathrm{L}$ reaction setup for miRNA qRT-PCR included about $5 \mathrm{ng}$ of diluted cDNA, $5 \mu \mathrm{L}$ of $2 \mathrm{X}$ QuantiTect SYBR Green PCR Mix (Qiagen, Hilden, Germany), $1 \mu \mathrm{L}$ of $10 \mathrm{X}$ miScript Universal primer and $1 \mu \mathrm{L}$ of $10 \mathrm{X}$ forward primer. The reaction was performed on ABI-7500PCR System (Applied Biosciences, CA, USA) with the recommended cycling parameters i.e. initial heat activation $\left(95^{\circ} \mathrm{C}\right.$ for $\left.15 \mathrm{~min}\right)$, followed by a total of 40 cycles of denaturation $\left(94{ }^{\circ} \mathrm{C}\right.$ for $\left.15 \mathrm{~s}\right)$, annealing $\left(55^{\circ} \mathrm{C}\right.$ for $\left.30 \mathrm{~s}\right)$ and extension $\left(70{ }^{\circ} \mathrm{C}\right.$ for $\left.30 \mathrm{~s}\right)$. Each miRNA assay was run in a quadruplet (in two sets of experiments of duplicate biological and technical replicates). For relative miRNA quantification, the expression was normalized to bovine RNU6 endogenous control.

For target genes quantitation, was $20-\mu \mathrm{L}$ reaction was setup for each gene assay (run in quadruplets) on Realtime PCR (7500 Applied Biosystems) with the same diluted cDNA $(\sim 5 \mathrm{ng})$ that was used for miRNA expression analysis, 2X QuantiTect SYBR Green PCR Mix $(10 \mu \mathrm{L}), 10$ pmol forward \& reverse primer $(2 \mu \mathrm{L}$ each) and RNase-free water. The cycle conditions were as follows: $15 \mathrm{~min}$ at $95^{\circ} \mathrm{C}$, followed by 40 cycles of $15 \mathrm{~s}$ at $94{ }^{\circ} \mathrm{C}, 40 \mathrm{~s}$ at $55^{\circ} \mathrm{C}$ and $40 \mathrm{~s}$ at $70^{\circ} \mathrm{C}$. Bovine GAPDH and beta-actin were used as normalization control and a no-template control was also included.

\section{Analysis of real-time qPCR data}

The SDS software version 2.3 (Applied Biosystems, USA) was used for calculating threshold cycle $(\mathrm{Ct})$ with baseline set at 0.2 threshold. Cycle threshold $(\mathrm{Ct})$ values 
Table 1 Sequence and reason of selection of the differentially expressed miRNAs used for validation

\begin{tabular}{lllll}
\hline SN & miRNA & miRNA primer name & Primer Sequence (5'-3') & Comments on the specific miRNA $^{\mathbf{a}}$ \\
\hline 1 & bta-miR-9-5p & BbuMir16-F & ucuuugguuaucuagcug & To compare Br-Mu with Ctrl-Mu \\
2 & bta-miR-677 & BbuMir19-F & cucacugaugagcagcuu & \\
3 & bta-miR-331-3p & BbuMir18-F & gccccugggccuauccua & To compare JD-Mu with Ctrl-Mu \\
4 & bta-miR-2440 & BbuMir21-F & ugcagugaugagacccug & \\
5 & Endogenous Control & BbuRNU6 & acgcaaauucgugaagcguu & \\
\hline
\end{tabular}

${ }^{\mathrm{B}} \mathrm{Br}-\mathrm{Mu}$ : Brucella infected buffaloes of Murrah breed

JD-Mu: Johne's Disease infected buffaloes of Murrah breed

Ctrl-Mu: Healthy buffaloes of Murrah breed

of miRNA or target genes were normalized to $\mathrm{Ct}$ values of endogenous controls as mentioned above for obtaining $\mathrm{dCt}$ values. Relative quantification $(\Delta \Delta \mathrm{Ct})$ was performed by calibrating the $\mathrm{dCt}$ values of the diseased samples with respect to $\mathrm{dCt}$ values of control samples [41]. The fold-change with respect to the calibrator has been depicted graphically. The error bars indicate standard errors. The $\mathrm{dCt}$ values were subjected to one-way ANOVA to determine significant differences $(P<0.05$, indicated by asterisks) between the healthy and diseased groups for the gene of interest (each miRNA and respective two target genes).

\section{Results}

\section{Identification of miRNAs in bubaline PBMCs}

We present the maiden report on in vivo study to identify and catalog the miRNA repertoire in water buffaloes, associated with Brucellosis and Johne's disease. The three sRNA sequence raw data-files (in fastq format)

Table 2 Detail of the designed primers used for qPCR validation of the selected miRNA-target genes vis-à-vis their functions

\begin{tabular}{|c|c|c|c|c|c|c|}
\hline SN & miRNA & $\begin{array}{l}\text { Target } \\
\text { Gene }\end{array}$ & Function of Target Gene & $\begin{array}{l}\text { Target gene Primer Name \& } \\
\text { Sequence }\left(5^{\prime}-3^{\prime}\right)\end{array}$ & $\begin{array}{l}\mathrm{Tm} \\
\left({ }^{\circ} \mathrm{C}\right)\end{array}$ & $\begin{array}{l}\text { Ampli-con } \\
\text { length }\end{array}$ \\
\hline \multirow[t]{2}{*}{1} & \multirow[t]{2}{*}{ bta-miR-9-5p } & \multirow{2}{*}{$\begin{array}{l}\text { Y-Box Binding } \\
\text { Protein } 3 \text { (YBX3) }\end{array}$} & \multirow{2}{*}{$\begin{array}{l}\text { Associated with binding of nucleic } \\
\text { acid, activation of transcription factor, } \\
\text { Sertoli-Sertoli cell junction related } \\
\text { pathways }\end{array}$} & YBX3-F: ccgcaatgccggtgagattg & 62 & \multirow[t]{2}{*}{187} \\
\hline & & & & YBX3-R: gtttggaccattggecgctt & 62 & \\
\hline \multirow[t]{2}{*}{2} & \multirow[t]{2}{*}{ bta-miR-9-5p } & \multirow[t]{2}{*}{$\begin{array}{l}\text { Sorting Nexin } 25 \\
\text { (SNX25) }\end{array}$} & \multirow{2}{*}{$\begin{array}{l}\text { Phosphatidylinositol binding and type } \\
\text { I transforming growth factor beta receptor } \\
\text { binding. }\end{array}$} & $\begin{array}{l}\text { SNX25-F: } \\
\text { aaatgcgecaaaacccgaca }\end{array}$ & 62 & \multirow[t]{2}{*}{185} \\
\hline & & & & SNX25-R: gcatttgctcgccgttctct & 62 & \\
\hline \multirow[t]{2}{*}{3} & \multirow[t]{2}{*}{ bta-miR-677 } & \multirow{2}{*}{$\begin{array}{l}\text { Nuclear Receptor } \\
\text { Subfamily 3, Group C, } \\
\text { Member } 1 \text { (NR3C1) }\end{array}$} & \multirow{2}{*}{$\begin{array}{l}\text { As transcription factor and also as } \\
\text { regulator of transcription factor; Mutations: } \\
\text { generalized glucocorticoid resistance }\end{array}$} & $\begin{array}{l}\text { NR3C1-F: } \\
\text { acctacgcagtgaaatgtcagact }\end{array}$ & 62 & \multirow[t]{2}{*}{162} \\
\hline & & & & $\begin{array}{l}\text { NR3C1-R: } \\
\text { gtttctccatatttggcattgctgt }\end{array}$ & 60 & \\
\hline \multirow[t]{2}{*}{4} & \multirow[t]{2}{*}{ bta-miR-677 } & \multirow{2}{*}{$\begin{array}{l}\text { Transmembrane } 9 \\
\text { Superfamily Member } 3 \\
\text { (TM9SF3) }\end{array}$} & \multirow{2}{*}{$\begin{array}{l}\text { Regulation of gene expression, } \\
\text { morphogenesis, and differentiation, } \\
\text { cell cycle progression. }\end{array}$} & $\begin{array}{l}\text { TM9SF3-F: } \\
\text { cgctatggtgtgtggcactg }\end{array}$ & 62 & \multirow[t]{2}{*}{170} \\
\hline & & & & $\begin{array}{l}\text { TM9SF3-R: } \\
\text { gctgacctgacagatttcggc }\end{array}$ & 62 & \\
\hline \multirow[t]{2}{*}{5} & \multirow[t]{2}{*}{$\begin{array}{l}\text { bta-miR-331- } \\
3 p\end{array}$} & \multirow{2}{*}{$\begin{array}{l}\text { Benzodiazepine Receptor } \\
\text { (Peripheral) Associated } \\
\text { Protein } 1 \text { (BZRAP1) }\end{array}$} & \multirow{2}{*}{$\begin{array}{l}\text { GPCR \& downstream signaling of B Cell } \\
\text { Receptor. } \\
\text { Association with diseases: amelogenesis- } \\
\text { imperfecta disease. }\end{array}$} & $\begin{array}{l}\text { BZRAP1-F: } \\
\text { acggctgtgctggagaactt }\end{array}$ & 62 & \multirow[t]{2}{*}{182} \\
\hline & & & & $\begin{array}{l}\text { BZRAP1-R: } \\
\text { caggcgatctcggcagatgt }\end{array}$ & 62 & \\
\hline \multirow[t]{2}{*}{6} & \multirow{2}{*}{$\begin{array}{l}\text { bta-miR-331- } \\
3 p\end{array}$} & \multirow{2}{*}{$\begin{array}{l}\text { Cleavage and } \\
\text { Polyadenylation } \\
\text { Specific Factor 2, } \\
100 \mathrm{kDa} \text { (CPSF2) }\end{array}$} & \multirow{2}{*}{$\begin{array}{l}\text { Gene expression and mRNA splicing pathways; } \\
\text { RNA binding. }\end{array}$} & CPSF2-F: cgctgctgaaccaacgtcag & 62 & \multirow[t]{2}{*}{187} \\
\hline & & & & $\begin{array}{l}\text { CPSF2-R: } \\
\text { cggtccaacaacaacaatccaaa }\end{array}$ & 60 & \\
\hline \multirow[t]{2}{*}{7} & \multirow[t]{2}{*}{ bta-miR-2440 } & \multirow{2}{*}{$\begin{array}{l}\text { RAB39B, Member } \\
\text { RAS Oncogene Family } \\
\text { (RAB39B) }\end{array}$} & \multirow{2}{*}{$\begin{array}{l}\text { Encodes a member of the Rab family of proteins } \\
\text { that are involved in vesicular trafficking. } \\
\text { Mutations: X-linked mental retardation. }\end{array}$} & $\begin{array}{l}\text { RAB39B-F: } \\
\text { acacgtccagccctaccaaa }\end{array}$ & 61 & \multirow[t]{2}{*}{189} \\
\hline & & & & $\begin{array}{l}\text { RAB39B-R: } \\
\text { aatagcgtctcgggctgacg }\end{array}$ & 62 & \\
\hline \multirow[t]{2}{*}{8} & \multirow[t]{2}{*}{ bta-miR-2440 } & $\begin{array}{l}\text { Ribosomal Modification } \\
\text { Protein RimK-Like Family }\end{array}$ & $\begin{array}{l}\text { Metabolism pathways and Alanine, aspartate } \\
\text { and glutamate metabolism; glutathione synthase }\end{array}$ & $\begin{array}{l}\text { RIMKLA-F: } \\
\text { ccttcgaccaggcatgcaac }\end{array}$ & 62 & 175 \\
\hline & & & $\begin{array}{l}\text { activity and } \mathrm{N} \text {-acetyl-L-aspartate-L-glutamate } \\
\text { ligase activity }\end{array}$ & $\begin{array}{l}\text { RIMKLA-R: } \\
\text { tagacgctctccgcaactcC }\end{array}$ & 62 & \\
\hline
\end{tabular}


have been submitted to NCBI-SRA (SRR3382673, SRR3382604, and SRR3383406).

The overview of miRNA sequencing data inclucing distribution of total initial reads, reads that mapped to miRbase, the number of known miRNAs identified, and number of novel miRNAs (i.e. miRNA sequences not reported in miRBase) is presented in tabular form (Table 3). A total of 274 miRNAs were identified across all the groups that matched to previously known miRNAs in bovine genome and additionally 36 novel mature* miRNAs (that originate from the less expressed arm of respective pre-miRNA) were identified. The list of identified mature miRNAs, its sequence and position as well as sequence their pre-miRNA; are provided in Supplementary files 1 and 2 .

Biocomputational analyses of the small RNA sequencing cataloged 258, 228 and 232 miRNAs in the BrMu, JDMu, and the control CtrlMu experimental groups, respectively (Supplementary file 4). It is evident from the Venn diagram (Fig. 1) that 195 miRNAs were common to all three groups. Some miRNAs (16, 3 and 18, respectively) were unique to each of the groups (Brucellosis, Johne's Disease and Healthy, respectively) (Fig. 1). The identification of uniquely expressed miRNAs specific to particular group suggests association with disease resistance or susceptibility.

\section{Differentially expressed miRNAs}

Group-wise distribution of the overall abundance of known miRNAs (log-transformed FPKM values) is shown as a box plot (Fig. 2). The mean abundance of the miRNAs was higher in the JD-Mu and control group than $\mathrm{Br}-\mathrm{Mu}$ group. The log expression levels of the known miRNAs (i.e. having taurine homolog) across the three groups are depicted by the heatmap (Fig. 3). In $\mathrm{Br}-\mathrm{Mu}$ group, bta-miR-191 and -21-5p had highest expression. While, bta-miR -2484 and 1434-5p were most abundantly expressed in the case of JD-Mu group. Likewise in Ctrl-Mu groups, miRNAs viz., bta-miR $-150,-19 b,-$ let-7a-5p, -223 , -let-7f were abundantly expressed along with high expression of bta-miR-191 and -21-5p. Most of the

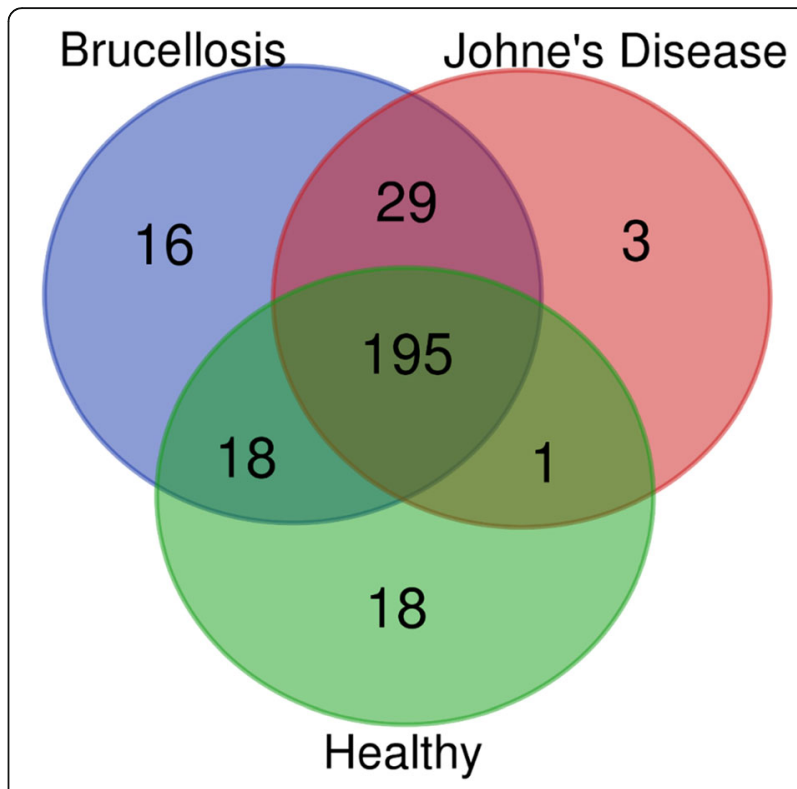

Fig. 1 Venn diagrams representing common and unique miRNAs across the three groups a) Brucellosis-positive buffaloes b) Johne's disease-positive buffaloes c) Healthy buffaloesprepared using an online tool (http://bioinformatics.psb.ugent.be/webtools/Venn)

identified miRNAs in the three groups had moderate to low expression levels.

The normalizied expression level of miRNAs were compared in the disease-groups and the healthy control group to identify differentially expressed miRNAs (Supplementary file 3). Based on the criteria of fold change of 1.5 or greater, only one miRNA i.e. bta-miR-1434-5p showed upregulation in Brucella infected ( $\mathrm{Br}-\mathrm{Mu})$ buffaloes. Whereas several miRNAs in this group were downregulated (fold change $\geq 2$ ), including bta-miR-27a-5p, $-2285 \mathrm{x}$ and $-34 \mathrm{~b}$, which exhibited more than 100 folds decreased expression as compared to healthy water buffaloes of control group (Ctrl-Mu).

Further, 3 miRNAs viz. bta-miR-1434-5p, -2340 and-2484 in Johne's diseased (JD-Mu) buffaloes group, were expressed at higher levels ( $>1.5$ folds) in comparison to Ctrl-Mu, of which bta-miR-1434-5p showed highest expression of 3.12 folds. Moreover, in

Table 3 Number of filtered reads number of reads matched to miRbase vis-à-vis total known and novel mature-star miRNAs identified in the four experimental samples

\begin{tabular}{llllll}
\hline SN & Group Name & Total Initial Reads & Reads matched to known mature miRNAs & Mature miRNAs & Novel mature* miRNAs \\
\hline $\mathbf{1}$ & $\mathbf{B r}-\mathbf{M u}$ & $2,676,675$ & 89,577 & 258 & 25 \\
$\mathbf{2}$ & JD-Mu & $2,288,179$ & 153,334 & 228 & 23 \\
$\mathbf{3}$ & Ctrl-Mu & 198,993 & 94,798 & 232 & 12 \\
\hline
\end{tabular}

Br-Mu: Brucellosis positive Murrah buffalo

JD-Mu: Johne's Disease positive Murrah buffalo

Ctrl-Mu: Healthy buffaloes (Control group) of Murrah breed mature* miRNAs: mature miRNAs that originate from alternative or less expressed strand of precursor miRNA hairpin structure 


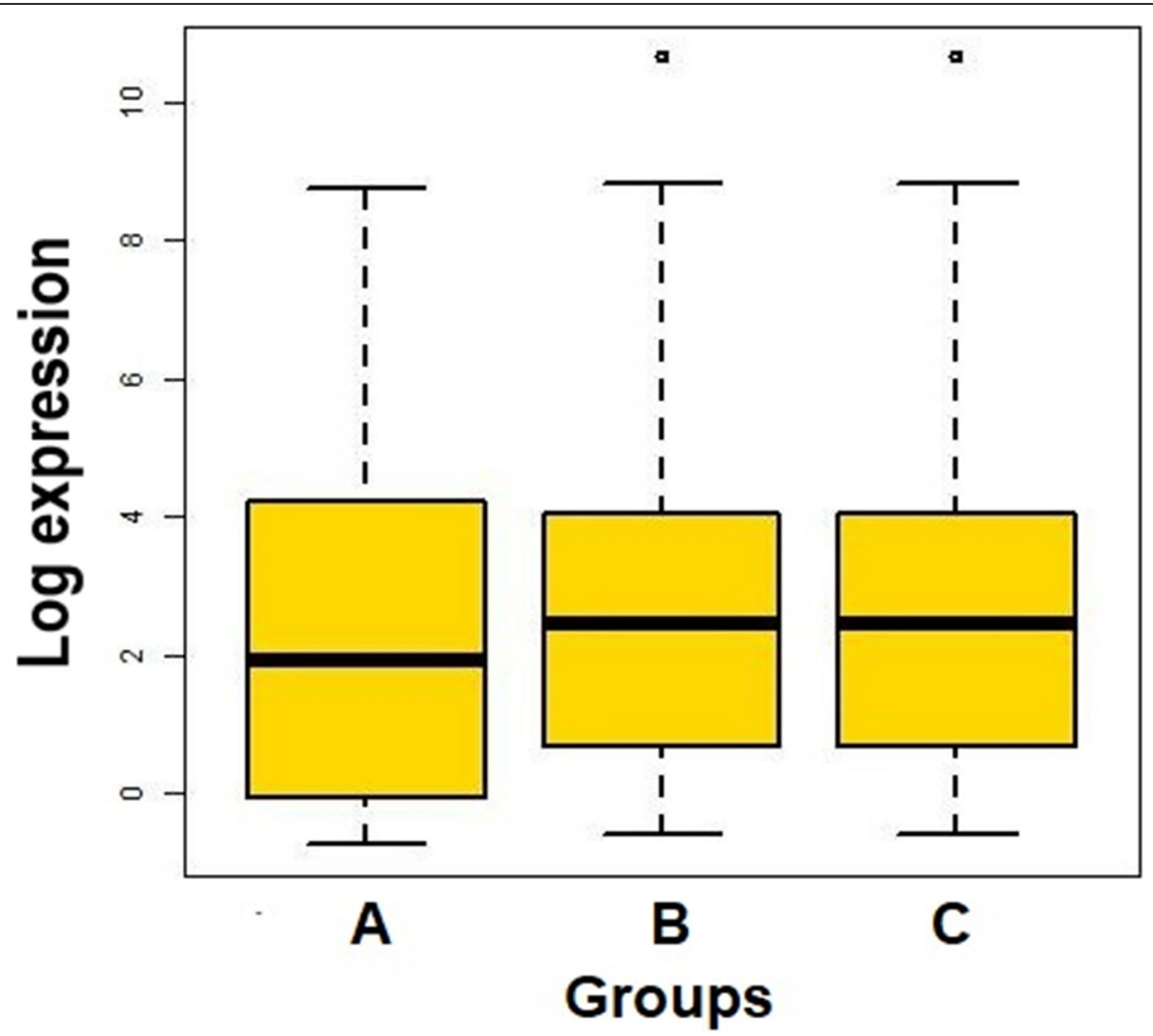

Fig. 2 Box-plot showing an abundance of known miRNAs across diseased and healthy control samples. The overall abundance of 275 known miRNAs expressed as log-transformed FPKM values distributed across the three groups a) Brucellosis-positive buffaloes b) Johne's disease-positive buffaloes c) Healthy buffaloes; shown as a box plot. The central line inside the boxes indicate median values, box width indicates 25 and $75 \%$ quartile ranges around the median, the termini indicate the 2.5 and 97.5 percentiles of the data, and the dots represent outliers

comparison to control group (Ctrl-Mu) of animals, many miRNAs were significantly down-regulated $(>2$ fold change). It was interesting to note that $11 \mathrm{miR}$ NAs within this group were downregulated from 30 to 52 times, with bta-miR-331-3p exhibiting utmost downregulation (51.5 folds) .

\section{Functional categorization of miRNA targets}

In order to further infer the role of differentially and uniquely expressed miRNAs in relation to disease, 937 gene targets were predicted by three online tools used in this study. The predicted targets were broadly classifed into biological processes and molecular functions (Fig. 4a and b) based on gene ontology (GO). The 1134 biological process hits includes 11 different pathway categories such as cellular processes (GO:0009987)- 29\%, metabolic processes (GO:0008152)- 22\%, biological regulation processes (GO:0065007)- 19\%, adhesion processes, response to stimulus, cell proliferation and immune responses etc. Further, 794 hits of molecular functions were divided into 8 pathway categories including of binding function (GO:0005488)-37\% and catalytic function (GO:0003824)- 31\%, among others.

\section{qPCR validation of selected differentially expressed miRNAs}

The real-time expression of the four selected miRNAs viz. bta-miR-9-5p, bta-miR-677, bta-miR-331-3p, and bta-miR-2440 were analyzed (normalized against endogenous control BbuRNU6). There was $\sim 0.4$ fold expression i.e. 2.5 times down-regulation of bta-miR-9-5p and $\sim 8$ fold increase in the expression of bta-miR-677, in $\mathrm{Br}-\mathrm{Mu}$ samples as compared to the healthy control (Ctrl-Mu). Further, bta-mir-331-3p and bta-mir-2440 showed 0.47 and 0.053-fold expression i.e. 2.12 and 18.87 times down-regulation, respectively, in JD-Mu as compared to the healthy control (Ctrl-Mu).

\section{qPCR validation of target genes}

Two target genes (that are expressed in blood cells) for each of the above-selected four miRNAs were also selected to compare the expression of the target genes with the respective targeting miRNAs. Normalization of the $\mathrm{Ct}$ values of the target genes was done separately with two endogenous controls: beta-actin and GAPDH. It is evident that the fold-change in the expression of target genes was higher with respect to beta-actin than that of 


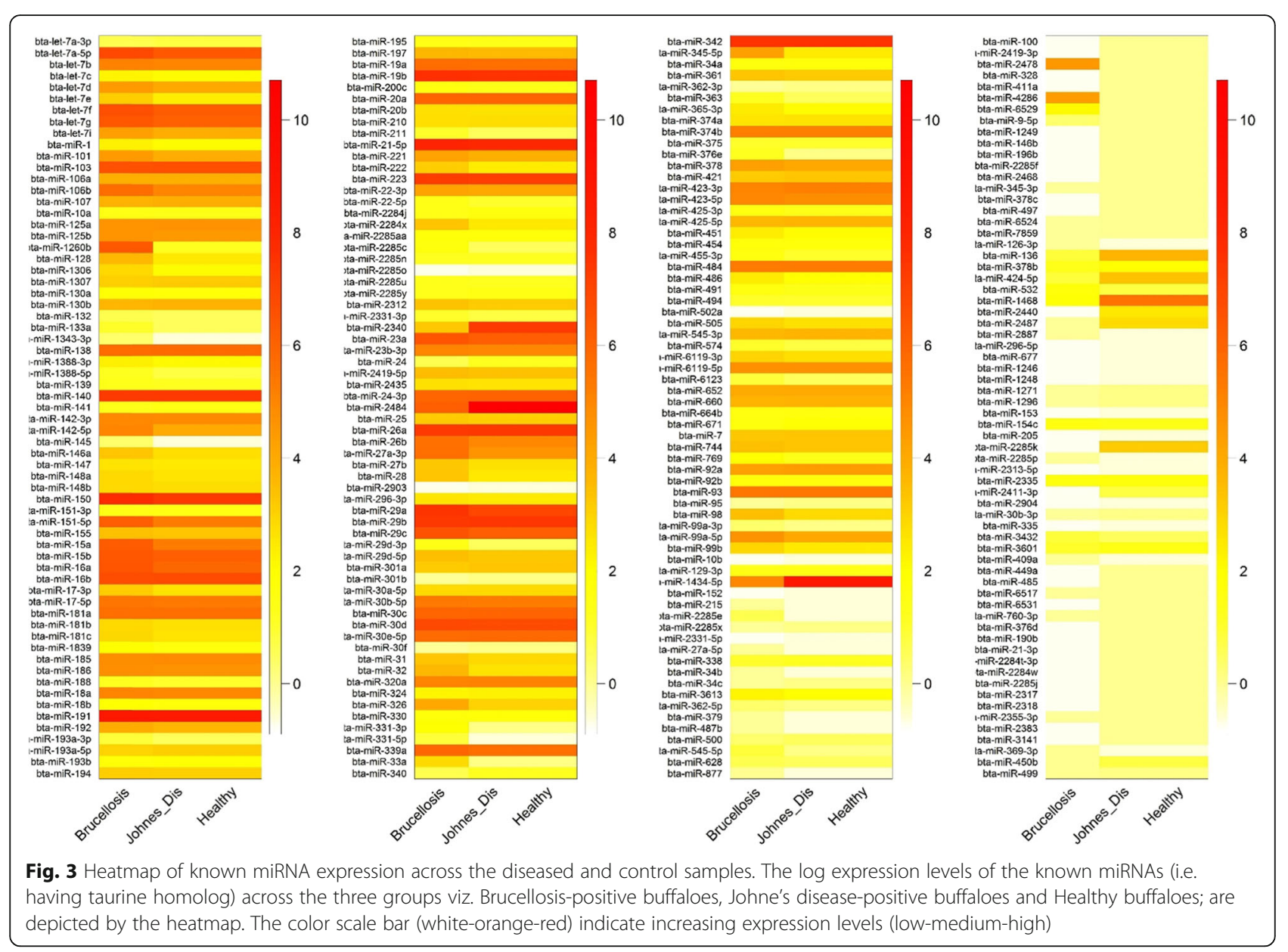

GAPDH as an endogenous control. The bta-miR-9-5p (down-regulated 2.5 times in $\mathrm{Br}-\mathrm{Mu}$ as compared to control) miRNA target genes viz. YBX3 and SNX25, showed up-regulated expression (2.09 and 5.14 folds) in $\mathrm{Br}-\mathrm{Mu}$ than in control with beta-actin as endogenous. The upregulated expression of SNX25 i.e. 5.14 folds, in $\mathrm{Br}-\mathrm{Mu}$ was significantly different $(P$ value $=0.0001)$ than in the control group. These target genes, YBX3 and SNX25, showed 0.63 and 1.84 fold change with respect to GAPDH, respectively. Similarly when comparing the $\mathrm{Br}-\mathrm{Mu}$ versus control, one of the target genes of miRNA bta-miR-677 (up-regulated 8 folds) i.e. TM9SF3 was found to be down-regulated 1.12 times with respect to beta-actin. While it showed significant (at $P$ value $=0.028$ ) downregulation of 5.31 folds) in $\mathrm{Br}-\mathrm{Mu}$ than in control, with respect to GAPDH. While it's second predicted target gene i.e. NR3C1 expression was found to be significantly ( $\mathrm{P}$ value $=0.004)$ up-regulated by 4.93 folds with respect to beta-actin. Moreover, it showed slightupregulation (1.09 folds) in $\mathrm{Br}-\mathrm{Mu}$ than in control, with respect to GAPDH.

In JD-Mu versus control group, the target genes viz. BZRAP1 and CPSF2; RAB39B and RIMKLA; showed down-regulated expression in JD-Mu with respect to control, even when both the miRNAs (bta-miR-331-3p and bta-miR-2440, respectively) were down-regulated in JD-Mu. Although the downregulation of both predicted targets of bta-miR-331-3p i.e. BZRAP1 and CPSF2 in JD-Mu were significantly different at $\mathrm{P}$ value $=0.021$ and 0.002 respectively, than in the control group.

The graph (Fig. 5) showed the expression of miRNAs normalized to RNU6 endogenous control along with their respective predicted target genes, normalized to beta-actin and GAPDH endogenous controls. The bars with the asterisk are significantly different at $P<0.05$ in the diseased group than in the healthy control group.

\section{Discussion}

Micro-RNAs (miRNAs) play a central role in regulating gene expression. Aberrant miRNA expression has been associated with human disease and pathological conditions, including cancer, neurodegenerative and cardiovascular diseases [42-44]. However, until now, a handful of studies have investigated the potential role of circulating miRNAs in infectious bacterial diseases [45-51]. Further, finding circulating miRNA signatures is more fascinating choice, for instance sampling is minimal 


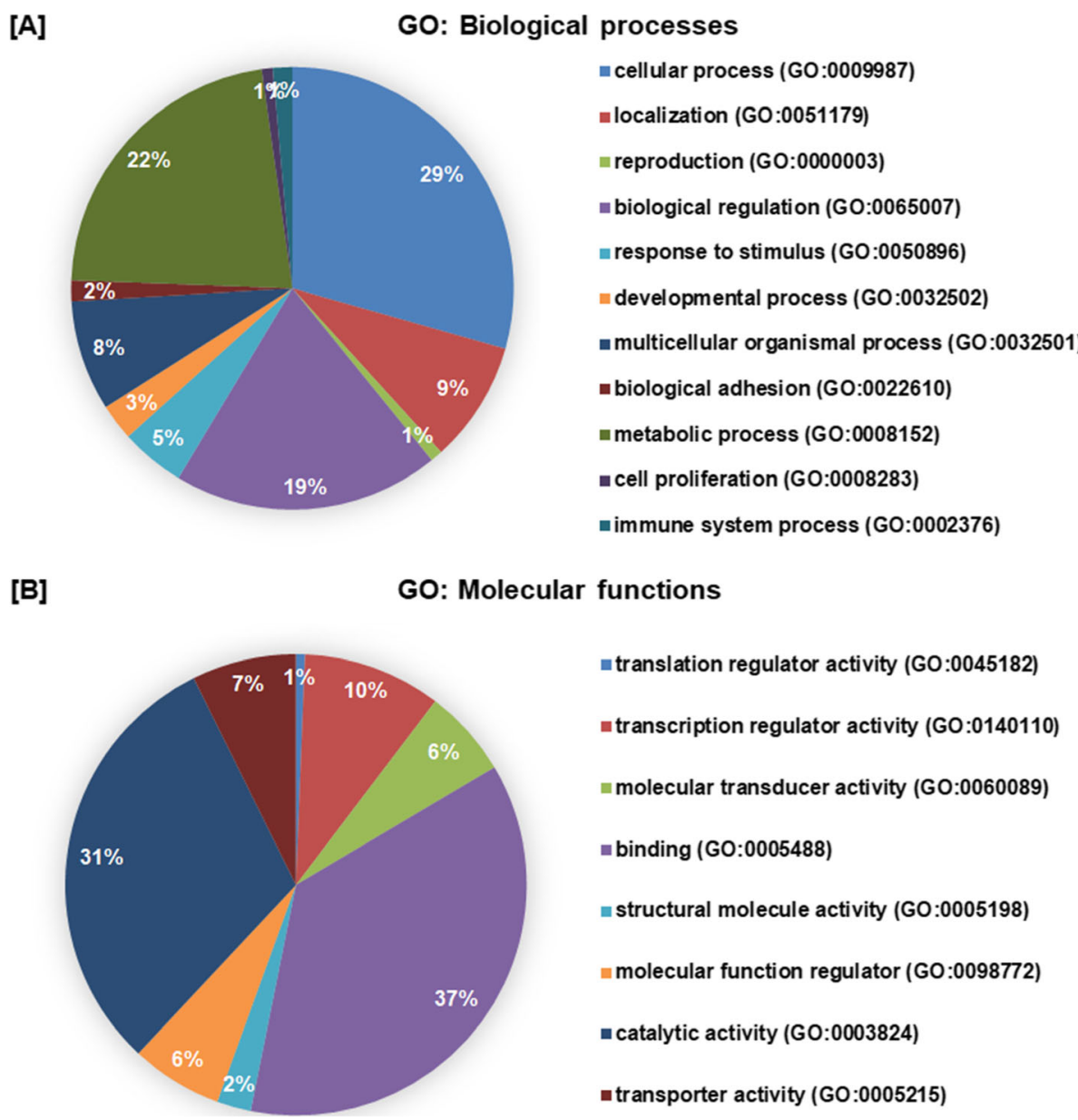

Fig. 4 Gene Ontology (GO) based classification of the miRNA targets. A total of 937 predicted miRNA-target genes were functionally classified into various categories biological processes (a) and molecular functions (b) using PANTHER Classification System (http://pantherdb.org/)

invasive and packaging of extracellular miRNAs within vesicles or their association with proteins makes them less susceptible to degradation $[13,52]$.

Our current work is the first-ever report on the cataloguing of differentially regulated miRNAs in PBMCs associated with Brucellosis and Johne's disease in Indian water buffaloes. Untill now, very limited literature is available regrading miRNA expression in response to bacterial infections of cattle. In one such study encompassing miRNA association with bovine mastitis, Lawless and co-workers identified 21 differentially expressed miRNAs by applying next-generation sequencing (NGS) approach in culture of bovine mammary epithelial cells challenged with Streptococcus uberis [53]. Jin and colleagues (2014) identified 231 known and 113 novel miRNAs associated with $S$. aureus or E. coli infections in vitro culture of bovine mammary epithelial cells (MAC-T cells). Five of these miRNAs viz. bta-mir-21-5p, $-22-3 p,-27 b,-184$ and let-7f had abundance greater than 50\% [51]. Among the top expressed miRNAs described above, we also found high expression of btamiR-21-5p and bta-let-7f in the PBMCs of Brucella infected water buffaloes.

Recently bovine TB associated miRNA profile was identified from the PBMC (stimulated with PPD-B) of unvaccinated and BCG-vaccinated cattle challenged with M. bovis [54, 55]. A core list of 88 known circulating miRNA including five (miR-22-3p, miR-92a, miR-191, miR-423-5p, and miR-486) most abundantly expressed miRNAs have been identified in the serum of cattle infected by Johne's disease [56]. The researchers further compared the miRNA expression before and after 6 months of infection and recorded 2 folds upregulation of bta-miR-205, and 2 folds downregulation of bta-miR- 432 post infection.

The results reported herein suggest that most of miRNAs including bta-miR-374a were downregulated in bubaline PBMCs upon infection with $M$. paratuberculosis, which is in agreement with the report on human by Sharbati and co-workers [55]. However, few miRNAs 


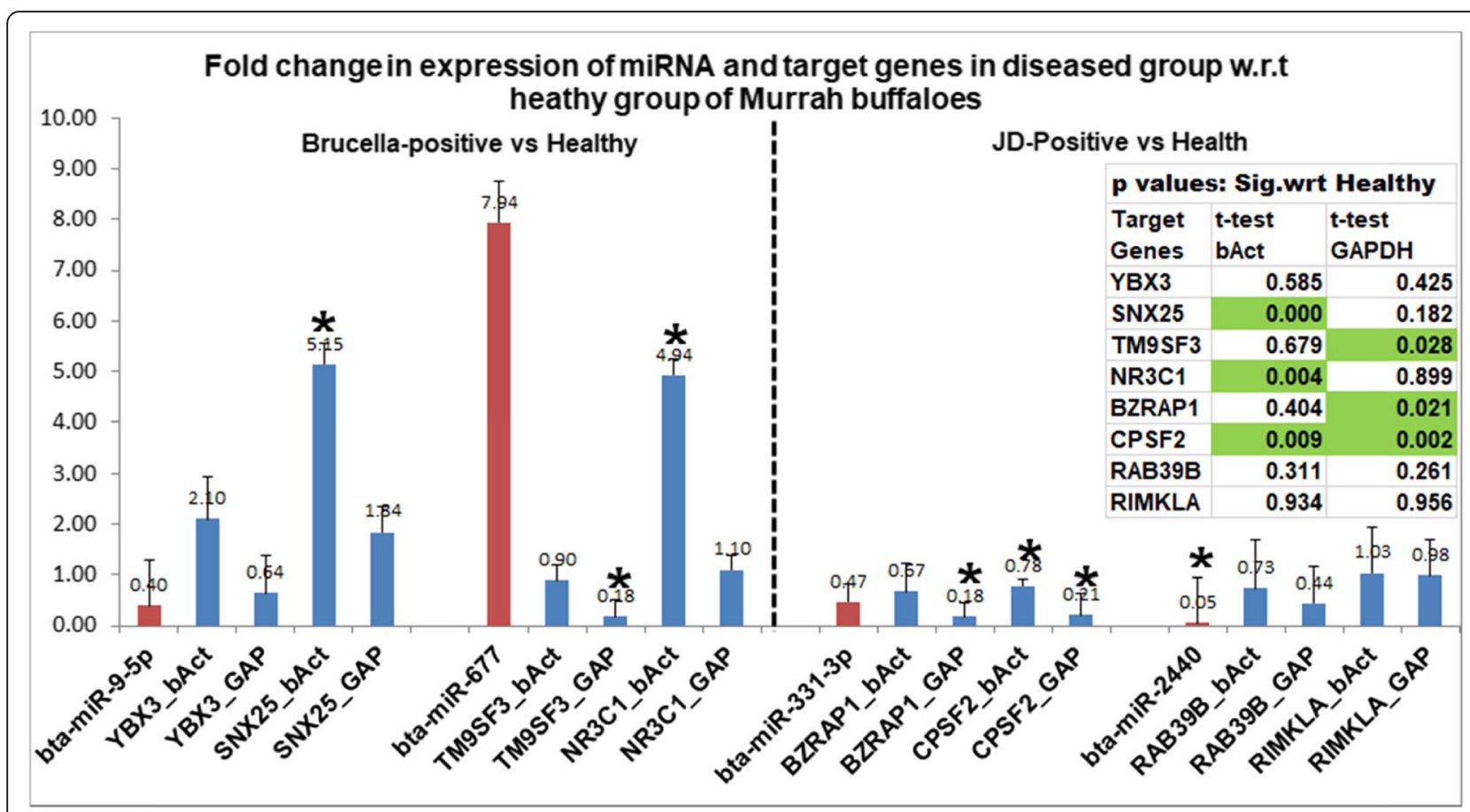

Fig. 5 Relative expression profiles of selected miRNAs and the corresponding target genes. The real-time expression of the four selected miRNAs viz. bta-miR-9-5p, bta-miR-677, bta-miR-331-3p, and bta-miR-2440 were analyzed and normalized against endogenous control BbuRNU6. Two target genes for each of the above-selected four miRNAs, i.e. 8 target genes, were analyzed and gene expression was normalized against two endogenous controls: GAPDH and beta-actin and represented as fold change in diseased vs. control group. Asterisks indicate statistically significant differences $\left({ }^{*} p<0.05\right)$ in diseased vs. healthy control group. The table indicating $P$ values is included in the figure

(bta-miR-191, bta-miR-1434-5p, bta-miR-2484 and btamiR-2340) exhibited increased expression in the PBMCs of M. paratuberculosis infected buffaloes. Out of these, bta-miR-191 was highly expressed in this group which corroborated by previous report in M. paratuberculosis infected cattle that described bta-miR-191 as most abundantly expressed miRNA [56].

We also identified and catalog the differentially expressed miRNAs, in PBMCs, related to Brucellosis disease in Indian water buffaloes. The results demonstrated modulation in miRNAs expression, 8 of which (viz. bta-miR-188, -200c, - 375, - 132, - 1343-3p 365-3p, -6123 and - 1434-5p) were up-regulated and more than 7 including bta-miR-9-5p, -27a-5p, -30f, $-34 b,-99 a-3 p,-2285 x$, and -6524 were downregulated in response to Brucella infection. The down-regulation was more than 10 folds. Interestingly as of now, only a single previous study indicated altered miRNA expression in the context of Brucella melitensis infection. The results demonstrate involvement of putative targets of dysregulated miRNAs (miR-92a, - 93, -181b - 1981 and let-7b) in various immune responses including cell death and autophagy [57]. Recently our lab explored the differentially expressed miRNAs in PBMCs culture, obtained from blood of Indian water buffaloes, challenged with ligands of toll like receptors viz. LPS, poly I:C, and CpG ODN to mimic the microbial infections and identified 160 mature and 130 novel miRNAs [58].

Microarrays are the one of the most extensively used method for studing transcriptional expression profiling. But, as microarrays are solution hybridization based assays, there is high variation in signal to noise ratio and less specificity. Hence, real-time PCR based techniques have been developed to detect precursor and mature miRNAs. Since miRNAs are present in minute quantity in serum and plasma, real-time PCR has been recognized as a promising technique for the detection and validation of blood circulating miRNAs as biomarkers [59]. Here in the present study, we used SYBR Green based qRT-PCR to the validate the NGS miRNA expression data. The same differential expression pattern (up or down-regulation) of miRNAs as observed by NGS were also seen by qPCR. For example, the bta-miR-9-5p and-331-3p that were observed to be down-regulated ( $\sim 12$ and $\sim 51$ folds, respectively) in $\mathrm{Br}-\mathrm{Mu}$ and JD-Mu, respectively, as compared to control; showed down-regulation (2.5 and 2.12 folds, respectively) by the qPCR with respect to RNU6 endogenous control. The miRNA bta-miR-677 that showed unique expression in $\mathrm{Br}-\mathrm{Mu}$ group by NGS, was observed 
to be expressed highly ( $\sim 8$ folds) in the respective group as compared to control by reverse transcriptase qPCR.

In the present study, a total of 8 predicted target genes for miRNA target expression were selected using three different tools based on their function in innate immunity and disease pathogenesis. Out of these, 3 predicted target genes viz. YBX3, SNX25, TM9SF3, followed the common negative regulatory function of miRNAs where up-regulated expression of miRNA in Brucella positive group resulted in the downregulation of target gene expression or vice versa. However, recent findings suggest that miRNAs can also promote the target gene expression in association with microRNP complexes [60, 61]. An example of such a remarkable association was observed herein study as well where NR3C1 was found to be upregulated in the Brucella positive group having upregulated bta-miR-677 expression. Likewise, in JD positive group, the down-regulated expression of target genes (BZRAP1 and CPSF2; RAB39B and RIMKLA) was observed even when the miRNAs (bta-miR-331-3p and bta-miR-331-3p, respectively) were downregulated.

\section{Conclusion}

In conclusion, our study unveiled first data on miRNA expression profile of healthy and diseased and water buffaloes associated with susceptibility of Johne's disease and Brucellosis. The study is likely to contribute significantly to understanding the role of miRNAs in the pathogenesis of bacterial infection as well as the identification of miRNA biomarkers for disease diagnosis and treatment.

\section{Supplementary information}

Supplementary information accompanies this paper at https://doi.org/10. 1186/s41544-020-00049-y.

\section{Additional file 1.}

Additional file 2.

Additional file 3.

Additional file 4.

\section{Abbreviations}

miRNAs: microRNAs; nt: nucleotide; PBMC: Peripheral blood mononuclear cells; sRNAs: small-RNAs; GO: Gene ontology; JD: Johne's disease; TB: Tuberculosis; Br: Brucellosis; Mu: Murrah breed; Ctrl: Control group; MAP: Mycobacterium avium subspecies paratuberculosis; ADRC: Animal Disease Research Centre; RBPT: Rose Bengal plate test; NGS: Next-generation sequencing; Panther: The Protein Analysis Through Evolutionary Relationships; BMEs: bovine mammary epithelial cells; TLR: Toll-like receptors

\section{Acknowledgments}

The authors are grateful to Dr. R Grewal, Incharge Dairy Farm (GADVASU), for extending help for sample collection and to Dr. Joydeep Mitra (GCC Biotech (India) Pvt. Ltd.) for providing NGS support.

\section{Authors' contributions}

JS: Sample collection \& processing, performed the experiments, manuscript writing; JKD: assistance in performing experiments; RKC, RSS: commented on the study, edited the manuscript; AS: Disease diagnosis; SK: helped in animal identification for blood samples; CSM: formulated the hypothesis, expression analysis, manuscript correction. All authors read and approved the final manuscript.

\section{Funding}

This work was financially supported by the Science and Engineering Research Board (SERB)-Department of Science and Technology (DST), Government of India (SERC-LS-293-2011, File Number SR/FT/LS-22/2011).

\section{Availability of data and materials}

All relevant data are within the paper and its Supporting files. The raw data file of miRNA-seq (in Fastq format) analysis has been published in the NCBISRA database and is available without any restriction for public use: SRR3382673 (Brucellosis-positive Murrah buffaloes), SRR3382604 (Johne's disease- positive Murrah buffaloes) and SRR3383406 (Healthy Murrah buffaloes)

\section{Ethics approval and consent to participate}

The recommendations of Institutional Animal Ethics Committee (IAEC), Guru Angad Dev Veterinary and Animal Sciences University (GADVASU) (VMC/12/ 3901-35; Dated 6th August' 2012) were followed for collection of blood samples.

\section{Consent for publication}

Not applicable.

\section{Competing interests}

The authors declare that they have no competing interests.

\section{Author details}

${ }^{1}$ College of Animal Biotechnology, Guru Angad Dev Veterinary and Animal Sciences University, Ludhiana, Punjab 141004, India. ${ }^{2}$ Present address: University Institute of Biotechnology (UIBT), Chandigarh University, Mohali, Punjab 140413, India. ${ }^{3}$ Department of Veterinary Pathology, Guru Angad Dev Veterinary and Animal Sciences University, Ludhiana, Punjab 141004, India. ${ }^{4}$ Department of Animal Genetics and Breeding, Guru Angad Dev Veterinary and Animal Sciences University, Ludhiana, Punjab 141004, India.

Received: 2 January 2020 Accepted: 29 April 2020

Published online: 22 May 2020

\section{References}

1. Hetta HF, Zahran AM, Shafik EA, El-Mahdy RI, Mohamed NA, Nabil EE, Esmaeel HM, Alkady OA, Elkady A, Mohareb DA, Hosni A, Mostafa MM, Elkady A. Circulating miRNA-21 and miRNA-23a expression signature as potential biomarkers for early detection of non-Small-cell lung Cancer. Microrna. 2019;8(3):206-15. https://doi.org/10.2174/ 1573399815666190115151500.

2. Gupta SK, Maclean PH, Ganesh S, Shu D, Buddle BM, Wedlock DN, Heiser A. Detection of microRNA in cattle serum and their potential use to diagnose severity of Johne's disease. J Dairy Sci. 2018;101(11):10259-70.

3. Malovrh $\breve{S}$, Kunej T, Kovač M, Dovč P. The microRNA gene bta-mir-2313 in cattle: an atlas of regulatory elements and an association analysis with growth and carcass traits in the Slovenian Simental cattle breed. Arch Anim Breed. 2018:61:271-8.

4. Lin X, Beckers E, Mc Cafferty S, Gansemans Y, Joanna Szymańska K, Chaitanya Pavani K, Catani JP, Van Nieuwerburgh F, Deforce D, De Sutter P, Van Soom A, Peelman L. Bovine embryo-secreted microRNA-30c is a potential non-invasive biomarker for hampered Preimplantation developmental competence. Front Genet. 2019;10:315. https://doi.org/10. 3389/fgene.2019.00315.

5. Ko J, Splitter GA. Molecular host-pathogen interaction in brucellosis, current understanding and future approaches to vaccine development for mice and humans. Clin Microbiol Rev. 2003:16:65-78.

6. Chiodini RJ, Van Kruiningen HJ, Merkal RS. Ruminant paratuberculosis (Johne's disease), the current status and future prospects. Cornell Vet. 1984; 74:218-62.

7. Windsor PA, Whittington RJ. Evidence for age susceptibility of cattle to Johne's disease. Vet J. 2010;184:37-44. 
8. Bower KL, Begg DJ, Whittington RJ. Culture of Mycobacterium avium subspecies paratuberculosis (MAP) from blood and extraintestinal tissues in experimentally infected sheep. Vet Microbiol. 2011;147:127-32.

9. Hostetter J, Steadham E, Haynes J, Bailey T, Cheville N. Phagosomal maturation and intracellular survival of Mycobacterium avium subspecies paratuberculosis in $\mathbf{J 7 7 4}$ cells. Comp Immunol Microbiol Infect Dis. 2003;26: 269-83

10. Weiss DJ, Evanson OA, McClenahan DJ, Abrahamsen MS, Walcheck BK Regulation of expression of major histocompatibility antigens by bovine macrophages infected with Mycobacterium avium subsp. paratuberculosis or Mycobacterium avium subsp. avium. Infect Immun. 2001;69:1002-8.

11. Mortier RAR, Barkema HW, Buck JD. Susceptibility to and diagnosis of Mycobacterium avium subspecies paratuberculosis infection in dairy calves: a review. Prev Vet Med. 2015;121:189-98.

12. Smith RL, Al-Mamun MA, Gröhn YT. Economic consequences of paratuberculosis control in dairy cattle: a stochastic modeling study. Prev Vet Med. 2017;138:17-27.

13. De Guire V, Robitaille R, Tétreault N, Guérin R, Ménard C, Bambace N, et al. Circulating miRNAs as sensitive and specific biomarkers for the diagnosis and monitoring of human diseases, Promises and challenges. Clin Biochem. 2013;46(10-11):846-60

14. Liang G, Malmuthuge N, Guan I L, Griebel P. Model systems to analyze the role of miRNAs and commensal microflora in bovine mucosal immune system development. Mol Immunol. 2015;66(1):57-67.

15. Vegh P, Magee DA, Nalpas NC, Bryan K, McCabe MS, Browne JA, et al. MicroRNA profiling of the bovine alveolar macrophage response to Mycobacterium bovis infection suggests pathogen survival is enhanced by microRNA regulation of endocytosis and lysosome trafficking. Tuberculosis (Edinb). 2015;95(1):60-7.

16. D'Alessandra Y, Paolo Devanna P, Limana F, Straino S, Carlo AD, Brambilla $P G$, et al. Circulating microRNAs are new and sensitive biomarkers of myocardial infarction. Eur Heart J. 2010;31:2765-73.

17. Yu DC, Li QG, Ding XW, Ding YT. Circulating MicroRNAs, potential biomarkers for cancer. Int J Mol Sci. 2011;12:2055-63.

18. Sui W, Ou M, Chen J, Li H, Lin H, Zhang Y, et al. microRNA expression profile of peripheral blood mononuclear cells of Klinefelter syndrome. Exp Ther Med. 2012;4:825-31.

19. Vendrell JP, Conge AM, Segondy M, Lombroso S, Huguet MF, Bertrand A, et al. In vitro antibody secretion by peripheral blood mononuclear cells as an expression of the immune response to Brucella spp. in humans. J Clin Microbiol. 1992;30:2200-3.

20. Giambartolomei GH, Delpino MV, Cahanovich ME, Wallach JC, Baldi PC, Velikovsky CA, et al. Diminished production of T helper 1 cytokines correlates with T cell unresponsiveness to Brucella cytoplasmic proteins in chronic human brucellosis. J Infect Dis. 2002;186:252-9.

21. Kazak E, Oliveira SC, Goral G, Akalin H, Yilmaz E, Heper Y, et al. Brucella abortus L7/L12 recombinant protein induces strong Th1 response in acute brucellosis patients. Iran J Immunol. 2010;7(3):132-41.

22. Almajid FM. Lymphocyte activation test for diagnosis of seronegative brucellosis in humans. Indian J PatholMicrobiol. 2011;54:775-81.

23. Coussens PM, Pudrith CB, Skovgaard K, Ren X, Suchyta SP, Stabel JR, Heegaard PM. Johne's disease in cattle is associated with enhanced expression of genes encoding IL-5, GATA-3, tissue inhibitors of matrix metalloproteinases 1 and 2, and factors promoting apoptosis in peripheral blood mononuclear cells. Vet Immunollmmunopathol. 2005;105(3-4):221-34.

24. Khalifeh MS, Stabel JR. Clinical disease upregulates expression of CD40 and CD40 ligand on peripheral blood mononuclear cells from cattle naturally infected with Mycobacterium avium subsp. paratuberculosis. Clin. Vaccine Immunol. 2013;20(8):1274-82. https://doi.org/10.1128/CVI.00246-13.

25. Eulalio A, Schulte L, Vogel J. The mammalian microRNA response to bacterial infections. RNA Biology. 2012;9:742-50. https://doi.org/10.4161/rna. 20018 PMID, 22664920

26. Mehta MD, Liu PT. microRNAs in mycobacterial disease, friend or foe? Front Genet. 2014;5:231. https://doi.org/10.3389/fgene.2014.00231 PMID, 25076967

27. Miotto P, Mwangoka G, Valente IC, Norbis L, Sotgiu G, Bosu R, et al. miRNA signatures in Sera of patients with active pulmonary tuberculosis. PLoS One. 2013;8:e80149. https://doi.org/10.1371/journal.pone.0080149.

28. Zhang H, Sun Z, Wei W, Liu Z, Fleming J, Zhang S, et al. Identification of serum microRNA biomarkers for tuberculosis using RNA-seq. PLoS One. 2014;9:e88909. https://doi.org/10.1371/journal.pone.0088909PMID 24586438.
29. Lecchi C, Catozzi C, Zamarian V, et al. Characterization of circulating miRNA signature in water buffaloes (Bubalus bubalis) during Brucella abortus infection and evaluation as potential biomarkers for non-invasive diagnosis in vaginal fluid. Sci Rep. 2019;9(1):1945. https://doi.org/10.1038/s41598-01838365-x.

30. Dhanoa JK, Singh J, Arora JS, Ramneek RSS, Mukhopadhyay CS. Identification of isomiRs Vis-à-Vis Functional Classification of the TargetGenes Associated with Brucellosis \& Paratuberculosis in Indian Water Buffaloes. San Diego, from 14th to 18th January' 2017. Poster Id: Poster presented in "Plant and Animal Genome XXV Conference", at Town and County Hotel and Conference Center; 2017. p. 23.

31. Dhanoa JK, Singh J, Singh A, et al. Discovery of isomiRs in PBMCs of diseased Vis-à-Vis healthy Indian water buffaloes. ExRNA. 2019;1:12. https:// doi.org/10.1186/s41544-019-0013-1.

32. Morgan W, MacKinnon D, Lawson J, Cullen G. The rose bengal plate agglutination test in the diagnosis of brucellosis. Vet Rec. 1969;85:636-41.

33. Vary PH, Andersen PR, Green E, Hermon-Taylor J, McFadden JJ. Use of highly specific DNA probes and the polymerase chain reaction to detect Mycobacterium paratuberculosis in Johne's disease. J Clin Microbiol. 1990; 28(5):933-7.

34. Mukhopadhyay CS, Verma R, Singh J. Extraction and gPCR based detection of miRNAs from cultured PBMCs of bubaline origin. [Mossman, Karen]. In: Innate Antiviral Immunity: Methods and Protocols, vol. 1656: Publisher Humana Press; 2017. https://doi.org/10.1007/978-1-4939-7237-1. Series ISSN: 1064-3745. eBook ISBN: 978-1-4939-7237-1, Hardcover ISBN: 978-1-4939-7236-4.

35. Langfelder $P$, Horvath S. WGCNA, an R package for weighted correlation network analysis. BMC Bioinformatics. 2008;9:559.

36. Agarwal V, Bell GW, Nam J-W, Bartel DP. Predicting effective microRNA target sites in mammalian mRNAs. Izaurralde E, ed. eLife. 2015;4:e05005. https://doi.org/10.7554/eLife.05005.

37. Wong N, Wang X. miRDB: an online resource for microRNA target prediction and functional annotations. Nucleic Acids Res. 2015:43:D146-52. https://doi.org/10.1093/nar/gku1104.

38. Wang $X$. Improving microRNA target prediction by modeling with unambiguously identified microRNA-target pairs from CLIP-ligation studies. Bioinformatics. 2016:32(9):1316-22.

39. Krek A, Grün D, Poy MN, Wolf R, Rosenberg L, Epstein EJ, et al. Combinatorial microRNA target predictions. Nat Genet. 2005;37(5):495-500. https://doi.org/10.1038/ng1536 PMID:15806104.

40. Mi H, Muruganujan A, Casagrande JT, Thomas PD. Large-scale gene function analysis with the PANTHER classification system. Nat Protoc. 2013;8: 1551-66. https://doi.org/10.1038/nprot.2013.092.

41. Livak KJ, Schmittgen TD. Analysis of relative gene expression data using real-time quantitative PCR and the 2(-Delta DeltaC (T)) method. Methods. 2001;25(4):402-8.

42. Croce CM. Causes and consequences of microRNA dysregulation in cancer. Nat Rev Genet. 2009;10:704-14.

43. Liu NK, Xu XM. MicroRNA in central nervous system trauma and degenerative disorders. Physiol Genomics. 2011;43:571-80.

44. Small EM, Olson EN. Pervasive roles of microRNAs in cardiovascular biology. Nature. 2011:469:336-42.

45. Fu Y, Yi Z, Wu X, Li J, Xu F. Circulating microRNAs in patients with active pulmonary tuberculosis. J Clin Microbiol. 2011;49:4246-51. https://doi.org/ 10.1128/JCM.05459-11 PMID, 21998423.

46. Abd-El-Fattah AA, Sadik NA, Shaker OG, Aboulftouh ML. Differential microRNAs expression in serum of patients with lung cancer, pulmonary tuberculosis, and pneumonia. Cell Biochem Biophys. 2013;67:875-84.

47. Qi Y, Cui L, Ge Y, Shi Z, Zhao K, Guo X, et al. Altered serum microRNAs as biomarkers for the early diagnosis of pulmonary tuberculosis infection. BMC Infect Dis. 2012;12:384. https://doi.org/10.1186/1471-2334-12-384 PMID, 23272999.

48. Zhang X, Guo J, Fan S, Li Y, Wei L, Yang X, et al. Screening and identification of six serum microRNAs as novel potential combination biomarkers for pulmonary tuberculosis diagnosis. PLoSOne. 2013;8:e81076. https://doi.org/10.1371/journal.pone.0081076 PMID, 24349033.

49. Yi Z, Fu Y, Ji R, Li R, Guan Z. Altered microRNA signatures in sputum of patients with active pulmonary tuberculosis. PLoS One. 2012;7(8):e43184 https://doi.org/10.1371/journal.pone.0043184.

50. Xu G, Zhang Z, Wei J, Zhang Y, Zhang Y, Guo L, et al. MicroR-142-3p downregulates IRAK-1 in response to Mycobacterium bovis BCG infection in macrophages. Tuberculosis. 2013;93:606-11. 
51. Jin W, Ibeagha-Awemu EM, Liang G, Beaudoin F, Zhao X, Guan I L. Transcriptome microRNA profiling of bovine mammary epithelial cells challenged with Escherichia coli or Staphylococcus aureus bacteria reveals pathogen directed microRNA expression profiles. BMC Genomics. 2014;15: 181. https://doi.org/10.1186/1471-2164-15-181.

52. Turchinovich A, Weiz L, Burwinkel B. Extracellular miRNAs, the mystery of their origin and function. Trends Biochem Sci. 2012;37:460-5. https://doi. org/10.1016/j.tibs.2012.08.003 PMID, 22944280.

53. Lawless N, Foroushani AB, McCabe MS, O'Farrelly C, Lynn DJ. Next generation sequencing reveals the expression of a unique miRNA profile in response to a gram-positive bacterial infection. PLoS One. 2013;8:e57543.

54. Golby P, Villarreal-Ramos B, Dean G, Jones GJ, Vordermeier M. MicroRNA expression profiling of PPD-B stimulated PBMC from M. bovis-challenged unvaccinated and BCG vaccinated cattle. Vaccine. 2014;32:5839-44. https:// doi.org/10.1016/j.vaccine.2014.07.034 PMID, 25107461.

55. Sharbati J, Lewin A, Kutz-Lohroff B, Kamal E, Einspanier R, Sharbati S. Integrated microRNA-mRNA-analysis of human monocyte derived macrophages upon Mycobacterium avium subsp hominissuis infection. PlosOne. 2011;6:e20258.

56. Farrell D, Shaughnessy RG, Britton L, MacHugh DE, Markey B, Gordon SV. The identification of circulating MiRNA in bovine serum and their potential as novel biomarkers of early Mycobacterium avium subsp paratuberculosis infection. PLoS One. 2015;10(7):e0134310. https://doi.org/10.1371/journal. pone.0134310

57. Zheng $K$, Chen DS, Wu YQ, Xu XJ, Zhang H, Chen CF, et al. MicroRNA expression profile in RAW264.7 cells in response to Brucella melitensis infection. Int J Biol Sci. 2012;8:1013-22.

58. Singh J, Mukhopadhyay CS, Kaur S, Malhotra P, Sethi RS, Choudhary RK. Identification of the microRNA repertoire in TLR-ligand challenged bubaline PBMCs as a model of bacterial and viral infection. PLoS One. 2016;11(6): e0156598. https://doi.org/10.1371/journal.pone.0156598.

59. Kang K, Peng X, Luo J, Gou D. Identification of circulating miRNA biomarkers based on global quantitative real-time PCR profiling. J Animal Sci Biotechnol. 2012;3:4.

60. Vasudevan S. Posttranscriptional upregulation by microRNAs. Wiley Interdisciplinary Reviews: RNA. 2012;3(3):311-30.

61. Huang V, Place RF, Portnoy V, Wang J, Qi Z, Jia Z, Yu A, Shuman M, Yu J, Li LC. Upregulation of Cyclin B1 by miRNA and its implications in cancer Nucleic Acids Res. 2012;40(4):1695-707. https://doi.org/10.1093/nar/gkr934.

\section{Publisher's Note}

Springer Nature remains neutral with regard to jurisdictional claims in published maps and institutional affiliations.

Ready to submit your research? Choose BMC and benefit from:

- fast, convenient online submission

- thorough peer review by experienced researchers in your field

- rapid publication on acceptance

- support for research data, including large and complex data types

- gold Open Access which fosters wider collaboration and increased citations

- maximum visibility for your research: over $100 \mathrm{M}$ website views per year

At BMC, research is always in progress.

Learn more biomedcentral.com/submissions 